\title{
Industrial-Based Time Performance of Assembly Cell Operators: Impact Assessment Characterization by Discrete-Event Simulation
}

\author{
Paulo Peças \\ IDMEC, Insituto Superior Técnico, \\ Universidade de Lisboa, Portugal. \\ Corresponding author: ppecas@ tecnico.ulisboa.pt \\ João Semeano \\ Insituto Superior Técnico, \\ Universidade de Lisboa, Portugal. \\ E-mail: jsemeano@gmail.com
}

(Received August 15, 2019; Accepted September 30, 2019)

\begin{abstract}
Assembly cells often depend on the human elements when an extended automation is not (economically, even if technologically) possible. The workers' natural variability is impossible to avoid in a manual assembly system. Usually when simulating an assembly system, a given task time distribution is assumed as the representation of the workers time performance. Workers have variations in their performance that can incur in the shifting of this distribution relative to the expected performance time distribution, as well as in the widening of this distribution, by the increase or decrease of dispersion. This paper presents a discrete event simulation model of an assembly system where the operators have different time distributions, aiming to assess their influence in the overall system performance. Those time distributions were obtained in industrial context, in a previous study, by observing workers in an assembly cell, so representing real performance of workers. The results indicate that the worst performing worker will "pace" the output system performance to a slower rhythm, while better performances of a single worker will only increase very slightly the system productivity.
\end{abstract}

Keywords- Assembly cells, Discrete-event simulation, Workers performance, Workers time performance, Variability

\section{Introduction}

Dealing with variability is a normal task when managing a manufacturing or assembly system (Tan, 1998). Different internal and external sources of variability influence the system performance with different impacts. In the present competitive context, where products have shorter life cycles (Kumar, 2019), have more model variety and demand uncertainty (external sources of variability), a full automation of the assembling system, even if technologically possible, might not be economically viable or feasible. As a result and despite all the innovations from the Industry 4.0 advent, the assembly systems keep being highly dependent on the workers for running several assembly tasks required for the final product. Therefore, there is an intrinsic variability in the assembling systems, introduced by the natural variability of manual work.

In the design phase of these assembling systems, the use of modelling and simulation is a recurrent strategy to estimate the system behaviour and for the early design decision-making process. Usually, these modelling and simulation developments focus on technological and operational aspects, in which operators are represented as resources performing specific tasks (Maczewska et al., 2019). Analytical and standard variability distributions are normally assigned to the simulated operators availability and/or to the tasks efficiency to introduce realism to the simulation (normal, triangular, Poisson, among others) (Lassila et al.,2005). The distribution parameters assigned are 
International Journal of Mathematical, Engineering and Management Sciences

Vol. 5, No. 1, 29-44, 2020

https://doi.org/10.33889/IJMEMS.2020.5.1.003

usually similar for all the workers, and are based on general behaviours ilustrated in literature. Nevertheless, for low automation assembly cells, several studies identify significant limitations of this approach, lacking in representing the real behaviour of the workers (Folgado et al., 2013; Folgado et al., 2013, 2015; Peltokorpi and Niemi, 2018).

Before going in detail about the paper content, it is important to explain the importance of DES. Simulation involves the development of descriptive computer models of a system and exercising those models to predict the operational behaviour and performance of the underlying system. DES is concerned with modelling a system by a representation in which state variables change instantaneously at separate points in time, directly associated with the beginning and end of events within a system (Altiok and Melamed, 2007). Performance analysis was one of the first manufacturing systems applications of DES, and has proven to be one of the most flexible and useful analysis tools in this field (Smith, 2003). In addition, DES is the standard tool used in the design of different automotive manufacturing (Carson, 2005) and has several advantages. It is particularly adept at compressing time to observe certain phenomena over long periods or expand time to observe a complex phenomenon in detail and experimenting with new or unknown situations about which only limited information is available. Such wide use gave birth of several software packages which the programming requires (Maria, 1997; Bahubalendruni et al., 2019).

Workers are expected to present individual differences among them, represented by variations both on the average time to perform the assigned tasks as well as on the dispersion of times with which they perform these tasks. It's more likely to obtain an inaccurate estimate of system productivity if one assumes that all workers come from a pool with productivity that is represented by a single average performance (Baines et al., 2004).

Studies addressing the impact on assembly systems of processing time variability have been published since the 1970's. These studies focused on the impact of positioning stations according to their level of processing time variability on asynchronous assembly cells/lines (Kala and Hitchings, 1973; Carnall and Wild, 1976; El-Rayah, 1979; Hillier and So, 1996; Pike and Martinj, 1994). Nonetheless, the input data is not industrial data, but rather educated guesses about the variability levels. In addition, it is often considered that the average task time each worker requires to fulfil the assembly is the same for all the workers, an assumption rejected by industrial data. These studies focus on asynchronous assembly cells but there is an apparent lack of research on the effects of time performance variability on assembly system configurations where the workers are not fixed in their positions, but rather move with the part - performing all the required tasks to complete the assembly cycle.

Some authors consider variability on task times in moving workers production systems, but model workers as identical (Bischak, 1996). They observed that if there is low processing time variability in balanced systems there is little blocking, so each additional worker adds capacity but does not significantly increase throughput time. With high variability in processing times additional workers increase the throughput of the system but also increase throughput time. With more workers in the system, workers make their way more slowly through the system, because they are blocked by more workers.

In this paper, data from an industrial setting is used as an example of the different time performances that can be found when performing manual high motor content assembly tasks. These several performances (slower/faster; higher/lower variability) are tested in different scenarios of 
International Journal of Mathematical, Engineering and Management Sciences

Vol. 5, No. 1, 29-44, 2020

https://doi.org/10.33889/IJMEMS.2020.5.1.003

workers allocation in an assembly cell. In the first scenarios, the same type of performance is considered for all the operators. The conclusions drawn from the analysis of such scenarios show that there is a proportional relationship between the deviation to the workers expected average task time performance and the system expected average time performance. With variability this relationship is not proportional. Other scenarios are tested, where the number of workers assigned to the assembly cell varies. This analysis helps to understand the effect of having more or less workers assigned to the assembly cell, varying the possibility of workers "bumping" into each other. The possibility of having a mix of different workers performances is also explored in this paper, which is more likely to happen in a real industrial setting. The analysis of these scenarios gives helpful insights on the impact of having "better than average"/ "worse than average" worker task time performances. Finally, from all the established scenarios, the authors propose practical guidelines to use in a daily assembly cell production management.

\section{Workers Time Performances Input Data}

Previous studies performed by the authors (Folgado et al., 2013; Folgado et al., 2015) indicate that, under the experimented conditions, the workers might have significant variations of both average time and variability when performing assembly tasks. Therefore, the worker performance can be assessed in terms of deviations to the workstation average population performance (for the average time and dispersion). A worker might have a task time performance slower or faster than the average and/or more or less dispersed than average. Given that, four types of performance can be considered in terms of deviations to the average values (Folgado et al., 2013; Folgado et al., 2015)

- The worker is slower completing the assembly task and the task times are more dispersed (with a lower consistency, meaning higher variability) than expected;

- The worker is faster completing the assembly task and the task times are more dispersed than expected;

- The worker is faster completing the assembly task and the task times are less dispersed (with a higher consistency, therefore less variability) than expected;

- The worker is slower completing the assembly task and the task times are less dispersed than expected.

These four combinations of two performance dimensions represent potential classes of workers performance, which can be set in quadrants, where the horizontal axis is the deviation to average time, and the vertical axis represents the deviation to the average time dispersion (see Figure 1).

According to the referred study, 46 time performances of fully trained workers on an industrial setting, performing assembly tasks, were registered. Their performances were compared with the overall average performance, by calculating the deviations to it. For more details please refer to work published by the authors (Folgado et al., 2013; Folgado et al., 2015). The centroid of performance in each quadrant was calculated, in order to find a quantitative representation of the average performance of each possible type of performance. It was observed that the average worker of Quadrant I took around $16 \%$ more time to complete the assembly cycle with about $26 \%$ more dispersion than the expected. A worker having an average performance in the opposite quadrant (Quadrant III) took approximately less $11 \%$ of the time with about $21 \%$ less dispersion, when compared with the expected values (see Table 1). 
International Journal of Mathematical, Engineering and Management Sciences

Vol. 5, No. 1, 29-44, 2020

https://doi.org/10.33889/IJMEMS.2020.5.1.003

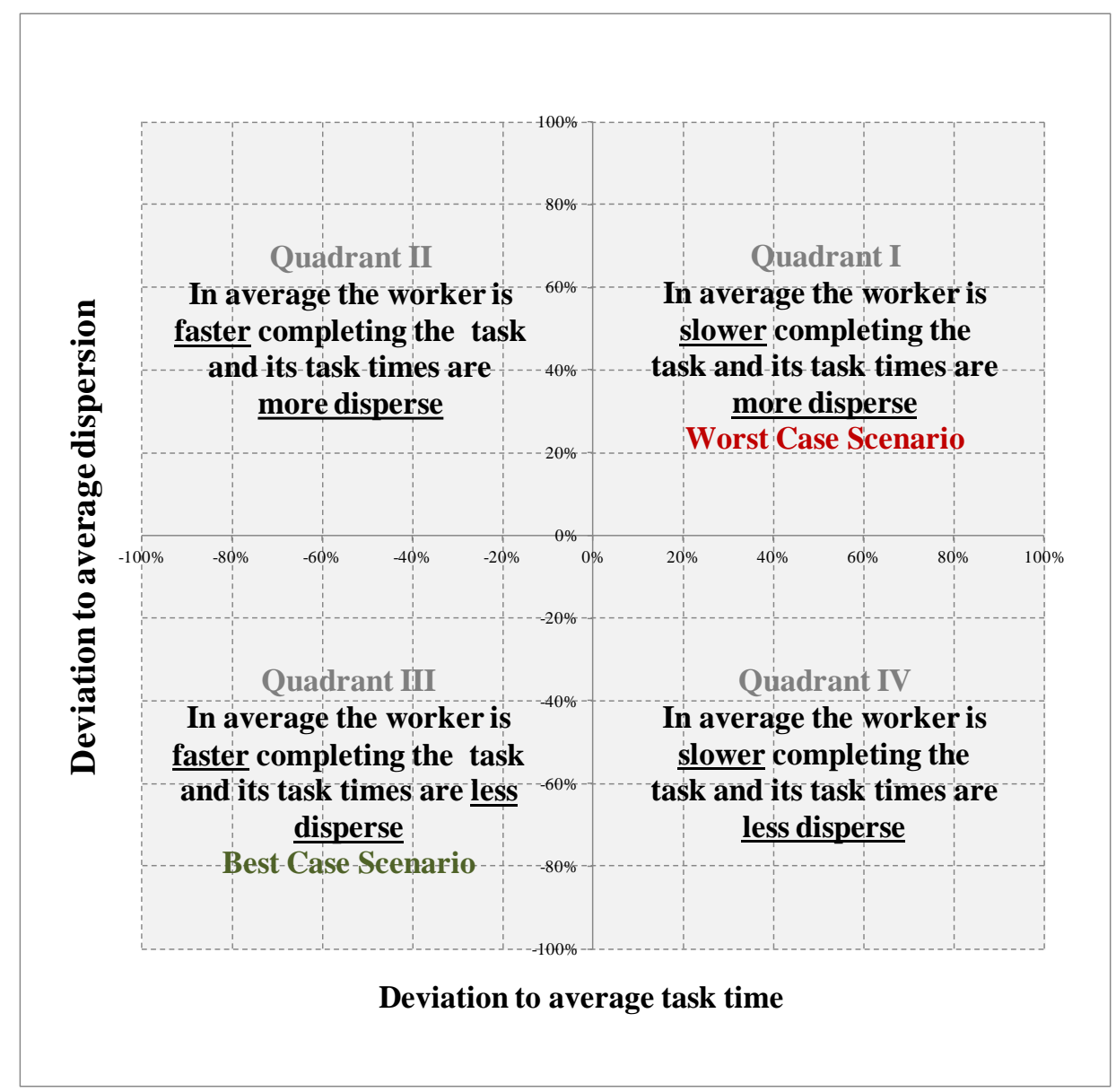

Figure 1. Workers performances graphic representation (adapted from Folgado et al., 2013; Folgado et al., 2015)

Table 1. Average deviation to expected performance (Folgado et al., 2013; Folgado et al., 2015)

\begin{tabular}{lcc}
\hline Type of Performance & Deviation to average & Deviation to dispersion \\
\hline Quadrant I & $+15.9 \%$ & $+26.4 \%$ \\
Quadrant II & $-4.5 \%$ & $+13.3 \%$ \\
Quadrant III & $-11.3 \%$ & $-21.4 \%$ \\
Quadrant IV & $+3.8 \%$ & $-9.1 \%$ \\
\hline
\end{tabular}

In the present study, it was considered that for a given type of assembly tasks of high motor content the expected average task time and standard deviation is 15 seconds and 1.95 seconds, respectively. Based on the average deviations calculated for each quadrant (centroids), the values for each class of workers performance can be assessed and compared with the expected values. A triangular centred task time distribution was used. Using the deviation to the average performance values, the minimum is calculated, as well as average and maximum times for each performance class (Table 2). It can be observed that the distribution of times changes significantly. Depending on the performance type, the time distribution can shift positively or negatively from the expected one, and/or can be wider or narrower - due to the variations in dispersion. 
International Journal of Mathematical, Engineering and Management Sciences

Vol. 5, No. 1, 29-44, 2020

https://doi.org/10.33889/IJMEMS.2020.5.1.003

Table 2. Time distributions calculated for each performance class (triangular distribution)

\begin{tabular}{lccc}
\hline Type of Performance & Min. [sec] & Average [sec] & Max. [sec] \\
\hline Expected & $\mathbf{1 0 . 2 2}$ & $\mathbf{1 5 . 0 0}$ & $\mathbf{1 9 . 7 8}$ \\
Quadrant I & $\mathbf{1 1 . 3 5}$ & $\mathbf{1 7 . 3 9}$ & $\mathbf{2 3 . 4 3}$ \\
Quadrant II & $\mathbf{8 . 9 1}$ & $\mathbf{1 4 . 3 3}$ & $\mathbf{1 9 . 7 4}$ \\
Quadrant III & $\mathbf{9 . 5 5}$ & $\mathbf{1 3 . 3 0}$ & $\mathbf{1 7 . 0 6}$ \\
Quadrant IV & $\mathbf{1 1 . 2 3}$ & $\mathbf{1 5 . 5 8}$ & $\mathbf{1 9 . 9 2}$ \\
\hline
\end{tabular}

Depending on the type of performance (Table 2), this assembly system can perform better or poorer than expected. The impact of having workers with significantly different performances should be considered in order to understand how and in what extension a given behaviour affects the system global performance.

\section{Simulation Model Used}

The model simulates an assembly cell with 8 workstations (Figure 2). It is assumed that every workstation has the same work content. This means that the tasks should take the same amount of time in each workstation. The task times only differ with the worker performance type (average and standard deviation). The travelling time between stations is assumed to be negligible and each worker has to pass through every workstation to complete the product assembly. To run different scenarios of performance, type the used distribution and its parameters must be defined. The distribution parameters used in the simulation are the ones described previously in Table 2.

Only one worker is permitted at one workstation. If a worker finishes his job at a certain workstation, but the following station is still occupied, the current workstation becomes free, and the worker can queue behind the worker using the following workstation. No worker can overtake another worker - it is considered that the assembly cell works with a chase logic (Miltenburg, 2001).

The model is prepared to accept different performance types for each worker. The number of workers can also be changed.

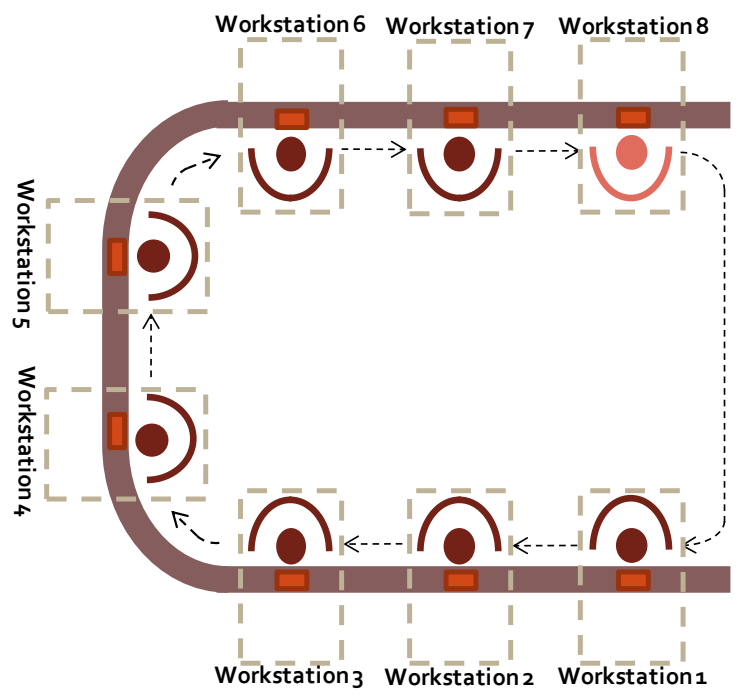

Figure 2. Assembly cell illustration 
International Journal of Mathematical, Engineering and Management Sciences

Vol. 5, No. 1, 29-44, 2020

https://doi.org/10.33889/IJMEMS.2020.5.1.003

\subsection{Model Development}

The simulation model was developed with the simulation software Arena, Version 12.0.0.0 (professional version). A line of blocks models each worker (Figure 3). The 'create' block introduces the parts to be processed in the system. The 'assign' and 'hold' blocks are used to control the simulation with a counter system that will be explained further on. The 'process' blocks represent the workstations. As the only input variables of performance are the workers specific performance details, these blocks contain the time distribution that characterizes each particular worker.

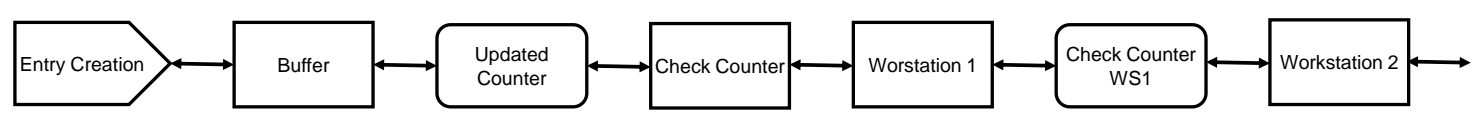

Figure 3. Created model detail

It is assumed that no worker should wait for a part at the start of the simulation to start working on a new part. This means that a large buffer was created so that a worker receives a new part as soon as he leaves workstation 8 . That worker is then enabled to start working as soon as workstation 1 is released.

As in any regular assembly cell system, only one worker can use a workstation at a given time. For the sake of this condition, one resource per workstation was introduced in the model. When a worker enters a workstation to perform the job, he seizes the respective resource and no other worker can use it.

Since it was considered on the studied system that no worker could overtake another one, a general counter system was designed. Each worker as a counter associated to him, and this counter is increased one unit every time he finishes a task in a workstation. A condition assured that the counter value of the worker ahead of the others was always bigger than the rest of them. Another condition was set so that the first worker to enter the system could only release the last workstation if the first workstation was released.

It was also assumed that when a worker finishes the task at the workstation, the workstation is released for the next worker to use. If a worker arrives at a seized workstation, he will wait for his turn 'behind' the worker performing the task in this workstation. If more workers arrive at this bottleneck workstation, a type FIFO (first in first out) queue will be created.

The workers can be easily added or removed to the model. To do so, it is necessary to add or subtract a line and adapt the re-entering condition of worker 1 to the total number of workers. To change the workers performance variables, one needs only to open the process block and change the time distribution parameters. Keeping in mind that each line represents a worker, each line must have the same parameters in every process.

\subsection{Studied Scenarios}

Several combinations of workers performances were tested (Table 3) in order to assess how the system performs under the influence of several worker behaviour classes: 
International Journal of Mathematical, Engineering and Management Sciences

Vol. 5, No. 1, 29-44, 2020

https://doi.org/10.33889/IJMEMS.2020.5.1.003

- Scenarios A: The assembly cell with a team of 7 workers, all with the same type of performance;

- Scenarios B: The assembly cell "overloaded" with a team of 8 workers, all with the same type of performance;

- Scenario C: The assembly cell with a team of 4 workers, all with the same type of performance.

- Scenarios D: The assembly cell with a team of 7 workers, where the number of workers with the best performance type (Quadrant III) varies;

- Scenarios E: The assembly cell with a team of 7 workers, where the number of workers with the worst performance type (Quadrant I) varies.

Table 3. Tested scenarios

\begin{tabular}{|c|c|c|c|c|c|c|}
\hline \multirow[b]{2}{*}{ Scenario } & \multirow[b]{2}{*}{$\mathrm{N}^{\circ}$ Workers } & \multicolumn{5}{|c|}{ Performance Type } \\
\hline & & Expected & Quadrant I & Quadrant II & Quadrant III & Quadrant IV \\
\hline A.0 & 7 & 7 & 0 & 0 & 0 & 0 \\
\hline A. 1 & 7 & 0 & 7 & 0 & 0 & 0 \\
\hline A. 2 & 7 & 0 & 0 & 7 & 0 & 0 \\
\hline A. 3 & 7 & 0 & 0 & 0 & 7 & 0 \\
\hline A. 4 & 7 & 0 & 0 & 0 & 0 & 7 \\
\hline B. 0 & 8 & 8 & 0 & 0 & 0 & 0 \\
\hline B. 1 & 8 & 0 & 8 & 0 & 0 & 0 \\
\hline B. 2 & 8 & 0 & 0 & 8 & 0 & 0 \\
\hline B. 3 & 8 & 0 & 0 & 0 & 8 & 0 \\
\hline B. 4 & 8 & 0 & 0 & 0 & 0 & 8 \\
\hline C.0 & 4 & 4 & 0 & 0 & 0 & 0 \\
\hline C. 1 & 4 & 0 & 4 & 0 & 0 & 0 \\
\hline C. 2 & 4 & 0 & 0 & 4 & 0 & 0 \\
\hline C. 3 & 4 & 0 & 0 & 0 & 4 & 0 \\
\hline C. 4 & 4 & 0 & 0 & 0 & 0 & 4 \\
\hline D. 1 & 7 & 6 & 0 & 0 & 1 & 0 \\
\hline D. 2 & 7 & 5 & 0 & 0 & 2 & 0 \\
\hline D. 3 & 7 & 4 & 0 & 0 & 3 & 0 \\
\hline D. 4 & 7 & 3 & 0 & 0 & 4 & 0 \\
\hline D. 5 & 7 & 2 & 0 & 0 & 5 & 0 \\
\hline D.6 & 7 & 1 & 0 & 0 & 6 & 0 \\
\hline E.1 & 7 & 6 & 1 & 0 & 0 & 0 \\
\hline E. 2 & 7 & 5 & 2 & 0 & 0 & 0 \\
\hline E. 3 & 7 & 4 & 3 & 0 & 0 & 0 \\
\hline E.4 & 7 & 3 & 4 & 0 & 0 & 0 \\
\hline E.5 & 7 & 2 & 5 & 0 & 0 & 0 \\
\hline E.6 & 7 & 1 & 6 & 0 & 0 & 0 \\
\hline
\end{tabular}

The objective of the scenarios in group A is to compare how would the system perform with workers with time performances of Quadrant I, II, III, IV and compare it with the system performance when all workers have "Expected" time performances. The testing in scenarios in groups $\mathrm{B}$ and $\mathrm{C}$ follows the same logic as in $\mathrm{A}$, but this time it is intended to assess the influence of the number of workers on the system performance (apart from number of produced parts).

With scenarios in groups $\mathrm{D}$ and $\mathrm{E}$, the changes to system performance are assessed when the number of workers with more extreme performances (of Quadrant III and Quadrant I) is increased while the number of workers with expected performance is reduced. 
International Journal of Mathematical, Engineering and Management Sciences

Vol. 5, No. 1, 29-44, 2020

https://doi.org/10.33889/IJMEMS.2020.5.1.003

\subsection{Measures of System Performance}

When evaluating a production system performance several measures of performance can be used. While it is important to assure that an assembly system is able to produce a given number of parts on average, the variability of the output also plays an important role on the system management on the short-term. Due to new production paradigms characterized by a rapidly changing environment, the planning period is shorter and the behaviour of the production cell in this short planning period determines how well the customer orders are met (Tan, 1999). In this paper, the focus was given to the average system cycle time (CT) and the variability of the system cycle times (SD) as measures of system performance.

In order to obtain the cycle time values, the simulation model is set to record the clock time each time a part leaves the system. The cycle time of each part is obtained by subtracting the successive times in which the parts leave the system. Then the variance is easily calculated, by calculating the average of the variances obtained for each run and applying the square root to this value, to obtain the cycle time standard deviation.

\section{Results}

In order to assess the impact of the different types of workers performance on the system, the system was simulated for $480 \mathrm{~min}$ ( $8 \mathrm{~h}$ hour shift). It was considered a $60 \mathrm{~min}$ warm-up period, to guarantee that the system was full when the results were collected. To assure results significance, each simulation was run 60 times.

\subsection{Scenarios A - 7 Workers, all with Same Time Performance}

The analysis of the average frequency per assembly system CT value (in each $1 \mathrm{sec}$ interval it was calculated the average frequency with which a part left the system) shows how the system cycle times are distributed for the different time performance scenarios (Figure 4). It can be observed that the interaction of the several workers in this system configuration, introduces some positive skewness on the output time distribution. When a worker cannot enter the following workstation, the rest of the workers tend to queue behind, and that time is not recoverable, therefore there is some "tail" in the right side of the distribution.

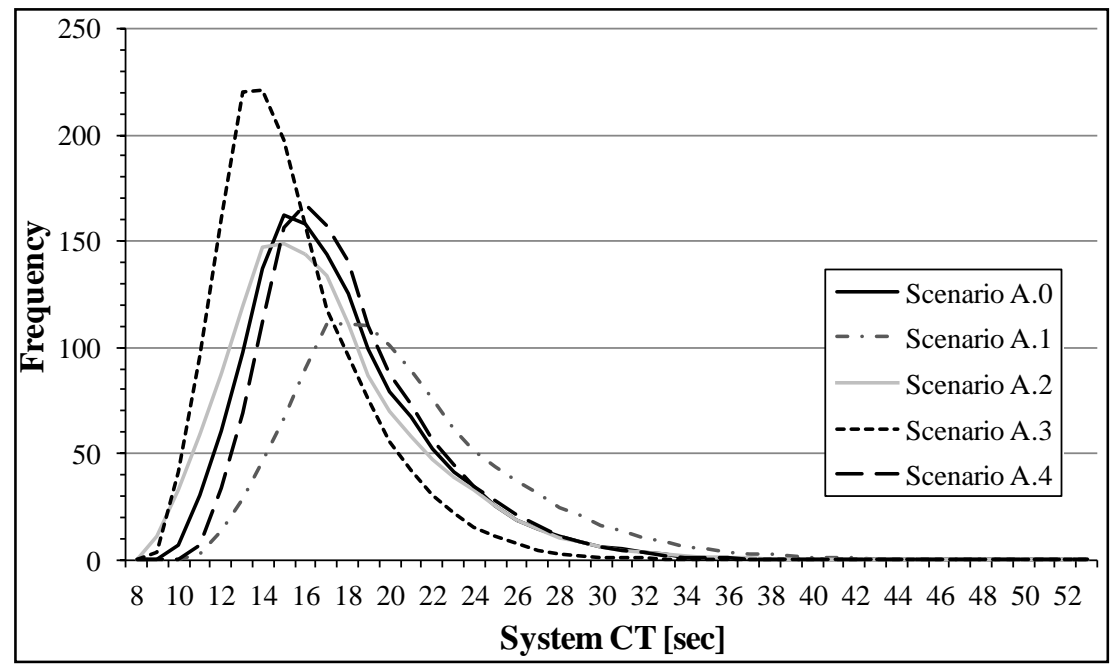

Figure 4. System cycle times output for Scenarios A 
International Journal of Mathematical, Engineering and Management Sciences

Vol. 5, No. 1, 29-44, 2020

https://doi.org/10.33889/IJMEMS.2020.5.1.003

When the system is evaluated with every worker performing within the expected time performance, in average the system produces $199 \mathrm{p} / \mathrm{h}$ according to the simulation output (Table 4). If this value is compared with the other scenarios of workers time performances, it can be observed that average output varies significantly. In scenario A.3 the system produces more $27 \mathrm{p} / \mathrm{h}$ when compared to A.0 (which corresponds to $13 \%$ more hourly production) while in scenario A.1 the system produces less 29 parts per hour than when all the workers perform as expected. Consequently, as the average time with which the workers are able to fulfil the assembly tasks increases the system average cycle time increases. In addition, as regards to output variability it can be observed that as the dispersion with which the workers are able to fulfil the assembly tasks increases the system cycle time dispersion increases. However, the effect of the variability tends to be amplified (see Figure 5 where the relation between worker performance deviation to the Expected is compared to the system output performance deviation to Scenario A.0).

Table 4. Scenarios A results - 7 workers

\begin{tabular}{lccccc}
\hline Tested Scenario & $\begin{array}{c}\text { Average } \\
\text { Output [p/h] }\end{array}$ & CT [sec] & SD [sec] & $\begin{array}{c}\text { Deviation to } \\
\text { A.0 CT }\end{array}$ & $\begin{array}{c}\text { Deviation to } \\
\text { A.0 SD }\end{array}$ \\
\hline A.0 - Expected & 199 & 18.08 & 4.19 & - & - \\
A.1 - Quadrant I & 170 & 21.11 & 5.15 & $17 \%$ & $23 \%$ \\
A.2 - Quadrant II & 205 & 17.54 & 4.54 & $-3 \%$ & $8 \%$ \\
A.3 - Quadrant III & 226 & 15.90 & 3.46 & $-12 \%$ & $-18 \%$ \\
A.4 - Quadrant IV & 193 & 18.61 & 4.00 & $3 \%$ & $-5 \%$ \\
\hline
\end{tabular}

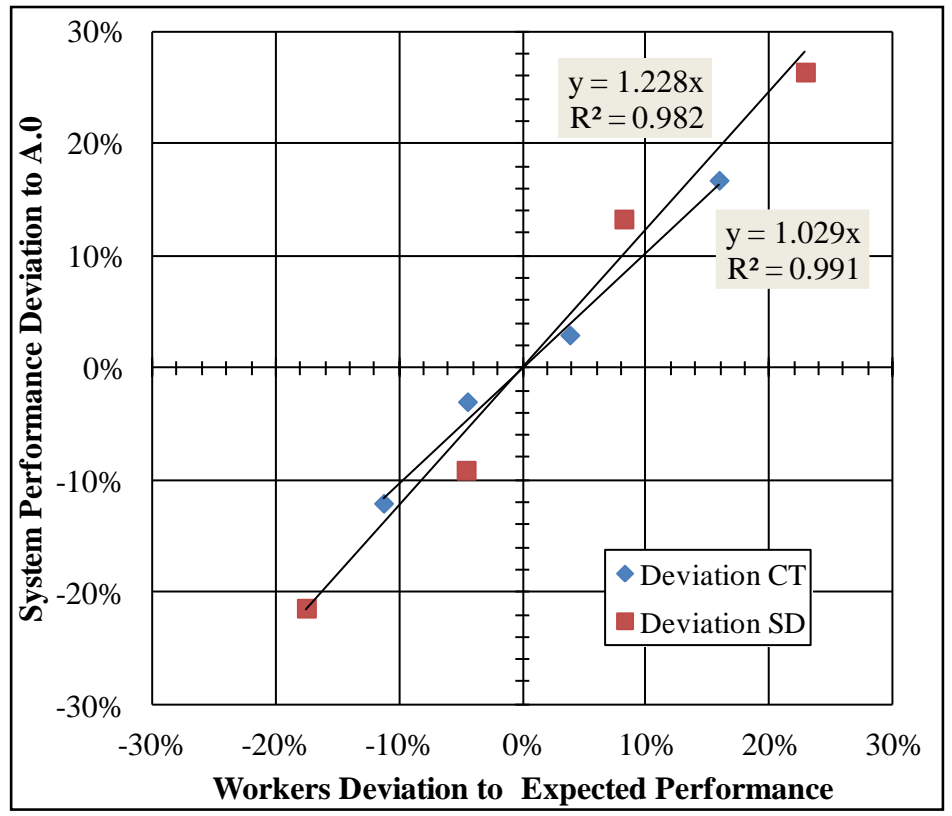

Figure 5. Relation between workers deviation to expected performance and system output for Scenarios A 
International Journal of Mathematical, Engineering and Management Sciences

Vol. 5, No. 1, 29-44, 2020

https://doi.org/10.33889/IJMEMS.2020.5.1.003

\subsection{Scenarios B and C-8 and 4 Workers, all with the Same Time Performance}

In Scenarios B a combination of 8 workers in the 8 workstation cell is tested. When managing/designing an assembly cell it is not advisable to put the same number of workers and workstations. The workers would most likely to interfere with each other (also because in reality the assembly tasks are not perfectly balanced). These scenarios were tested in order to understand how the number of workers might affect the system performance measures, and more objectively to simulate a scenario where the workers interference with each other is more likely to happen. It is expectable that by increasing the number of workers, the average number of parts produced per hour will increase, since there is no time "gap" between workers. When scenario B.0 (Table 5) is compared to A.0, by introducing one more resource, the average cycle time reduces $8 \%$ (and in average the system produces more 18 parts per hour, but the worker productivity in parts/worker/hour reduces 5\%). The SD for scenarios B decreases more than $20 \%$ in every scenario $\mathrm{B}$, but it is expected since the CT decreased as well. The variability of output reduces because every workstation is occupied at all times by a worker, which is not the case in scenarios A. When the relation between the workers deviation to expected performance is plotted against the system performance deviation to B.0 (Figure 6), it can be observed that this relation is well approximated by a linear relation for both $\mathrm{CT}$ and $\mathrm{SD}$.

Table 5. Scenarios B results - 8 workers

\begin{tabular}{|c|c|c|c|c|c|}
\hline Tested Scenario & $\begin{array}{c}\text { Average } \\
\text { Output }[\mathrm{p} / \mathrm{h}]\end{array}$ & $\mathrm{CT}[\mathrm{sec}]$ & $\mathrm{SD}[\mathrm{sec}]$ & $\begin{array}{c}\text { Deviation to } \\
\text { B.0 CT } \\
\end{array}$ & $\begin{array}{c}\text { Deviation to } \\
\text { B.0 SD }\end{array}$ \\
\hline B.0-Expected & 217 & 16.58 & 3.09 & - & - \\
\hline B.1 - Quadrant I & 185 & 19.38 & 3.91 & $17 \%$ & $26 \%$ \\
\hline B.2 - Quadrant II & 223 & 16.12 & 3.50 & $-3 \%$ & $13 \%$ \\
\hline B.3 - Quadrant III & 247 & 14.54 & 2.43 & $-12 \%$ & $-21 \%$ \\
\hline B.4 - Quadrant IV & 211 & 17.02 & 2.81 & $3 \%$ & $-9 \%$ \\
\hline
\end{tabular}

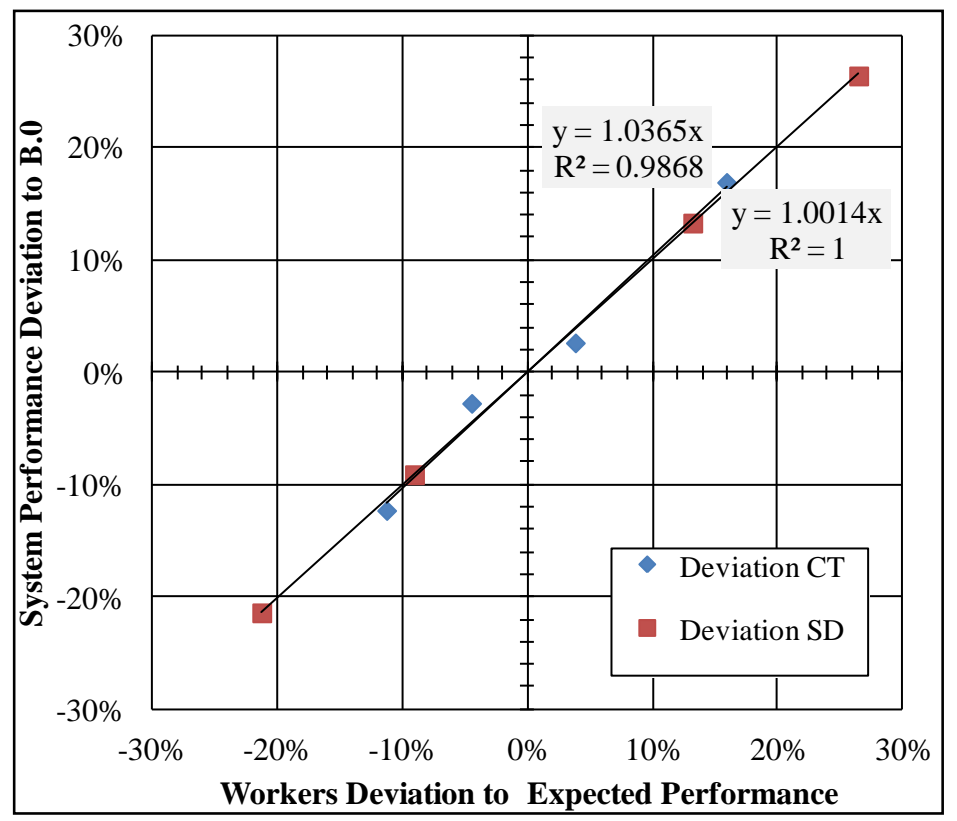

Figure 6. Relation between workers deviation to expected performance and system output for Scenarios B 
International Journal of Mathematical, Engineering and Management Sciences

Vol. 5, No. 1, 29-44, 2020

https://doi.org/10.33889/IJMEMS.2020.5.1.003

In scenarios $\mathrm{C}$ there are only 4 workers in the assembly system. The average CT increases in every scenario as expected when compared to $\mathrm{A}$ and $\mathrm{B}$, as well as the SD. The output variability increases greatly since the operators tend to be queued one after the other, so there are larger time intervals that no part is leaving the system (Table 6).

When scenario C.0 is compared to A.0, by reducing the number of resources the average cycle time increases 68\%, and in average the system produces less 81 parts per hour, but the worker productivity in parts/worker/hour increases $4 \%$. The worker productivity increases since the workers are less likely to interfere with each other. In addition, the relation between the workers deviation to expected performance and system performance deviation to C.0 is no longer described perfectly by a linear interpolation in the case of the SD (Figure 7).

Table 6. Scenarios $\mathrm{C}$ results -4 workers

\begin{tabular}{lccccc}
\hline Tested Scenario & $\begin{array}{c}\text { Average } \\
\text { Output [p/h] }\end{array}$ & CT [sec] & SD [sec] & $\begin{array}{c}\text { Deviation to } \\
\text { C.0 CT }\end{array}$ & $\begin{array}{c}\text { Deviation to } \\
\text { C.0 SD }\end{array}$ \\
\hline C.0 - Expected & 118 & 30.32 & 13.11 & - & - \\
C.1 - Quadrant I & 102 & 35.24 & 15.73 & $16 \%$ & $20 \%$ \\
C.2 - Quadrant II & 123 & 29.10 & 12.94 & $-4 \%$ & $-1 \%$ \\
C.3 - Quadrant III & 134 & 26.84 & 11.58 & $-12 \%$ & $-12 \%$ \\
C.4 - Quadrant IV & 114 & 31.42 & 13.40 & $4 \%$ & $2 \%$ \\
\hline
\end{tabular}

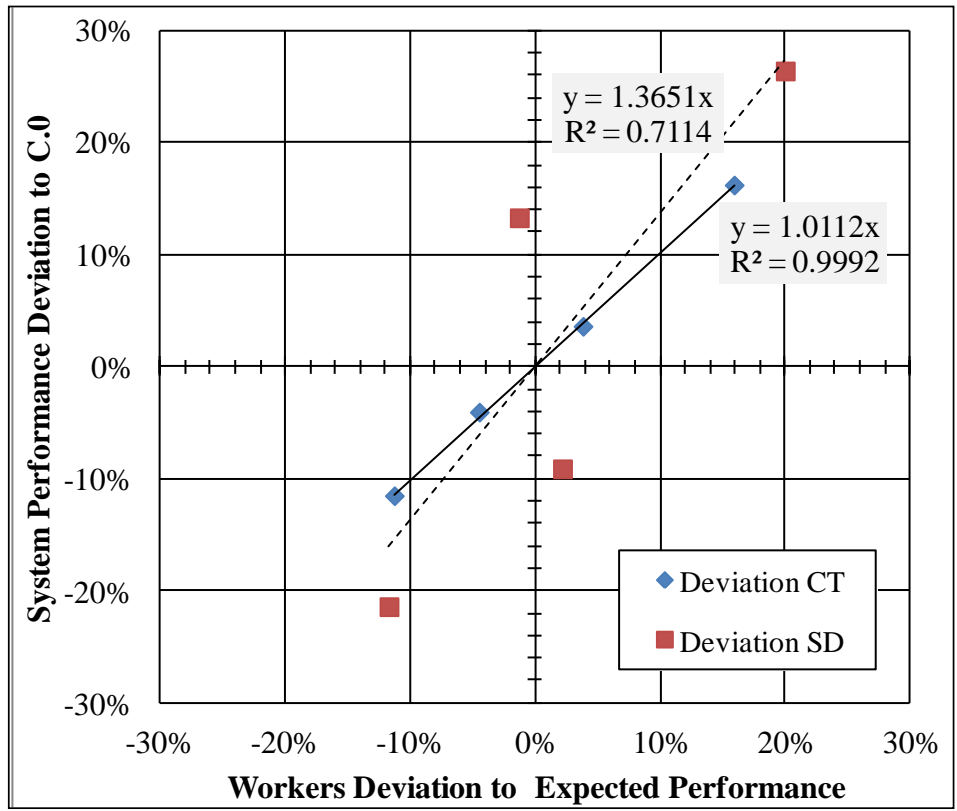

Figure 7. Relation between workers deviation to expected performance and system output for Scenarios C 
International Journal of Mathematical, Engineering and Management Sciences

Vol. 5, No. 1, 29-44, 2020

https://doi.org/10.33889/IJMEMS.2020.5.1.003

The workers might have significant differences between them. Therefore, it is important to understand how in a scenario where there are different performances within the same team of workers, the system will react. In scenarios A, B and C it was verified that the number of workers working in the assembly cell influence (not only) the total number of parts produced, the worker productivity but also the variability on the cycle time. In scenarios $\mathrm{D}$ and $\mathrm{E}$, it is tested the effects of having heterogeneity of workers performance, in a team of 7 workers in the 8 workstation assembly cell.

\subsection{Scenarios D - 7 Workers, with Variable Number of Workers with Quadrant III Performances}

In these scenarios there are 7 workers in the assembly cell and the number of workers with the best performance (Quadrant III) is successively increased from 1 to 6, while the remaining workers have Expected performance (Table 7). The simulations output show that each time a worker with Expected performance is substituted by a worker with Quadrant III performance the average number of parts per hour increases slightly (when compared to scenario A.0). Consequently, the same conclusions are taken for the average system CT. Nevertheless, the significant increase happens when there is no longer any worker with Expected performance (scenario A.3). This happens because the slowest worker is the one causing queuing behind him, and delaying the parts flow. This effect can be observed graphically when the histogram is plotted: there is a smooth bell shaped curve on the right side of the histogram (Figure 8), concentrated on higher CTs.

Unlike the low impact on the average CT, the substitution of workers with Expected time performance by Quadrant III time performances, causes a significant increase on the SD. It increases successively, as Quadrant III workers are included, reaching its maximum when there are 6 workers with Quadrant III performance and 1 with Expected performance. When all the workers have Quadrant III performance, there is no longer a "slower" and "more disperse" worker (when compared to Quadrant III) widening the system CTs distribution.

Table 7. Scenarios D simulation output compared with A.0 and A.3

\begin{tabular}{|c|c|c|c|c|c|}
\hline Tested Scenario & $\begin{array}{c}\text { Average } \\
\text { Output }[\mathrm{p} / \mathrm{h}]\end{array}$ & $\mathrm{CT}[\mathrm{sec}]$ & $\mathrm{SD}$ [sec] & $\begin{array}{c}\text { Deviation to } \\
\text { A.0 CT }\end{array}$ & $\begin{array}{c}\text { Deviation to } \\
\text { A.0 SD }\end{array}$ \\
\hline A.0-Expected & 199 & 18.08 & 4.19 & - & - \\
\hline D.1 - 1 Quadrant III & 200 & 17.95 & 4.66 & $-1 \%$ & $11 \%$ \\
\hline D. $2-2$ Quadrant III & 202 & 17.82 & 5.14 & $-1 \%$ & $23 \%$ \\
\hline D.3 - 3 Quadrant III & 203 & 17.67 & 5.59 & $-2 \%$ & $33 \%$ \\
\hline D.4 - 4 Quadrant III & 205 & 17.51 & 6.17 & $-3 \%$ & $47 \%$ \\
\hline D.5 - 5 Quadrant III & 207 & 17.36 & 6.95 & $-4 \%$ & $66 \%$ \\
\hline D.6-6 Quadrant III & 209 & 17.15 & 7.98 & $-5 \%$ & $90 \%$ \\
\hline A.3 - 7 Quadrant III & 226 & 15.90 & 3.39 & $-12 \%$ & $-19 \%$ \\
\hline
\end{tabular}


International Journal of Mathematical, Engineering and Management Sciences

Vol. 5, No. 1, 29-44, 2020

https://doi.org/10.33889/IJMEMS.2020.5.1.003

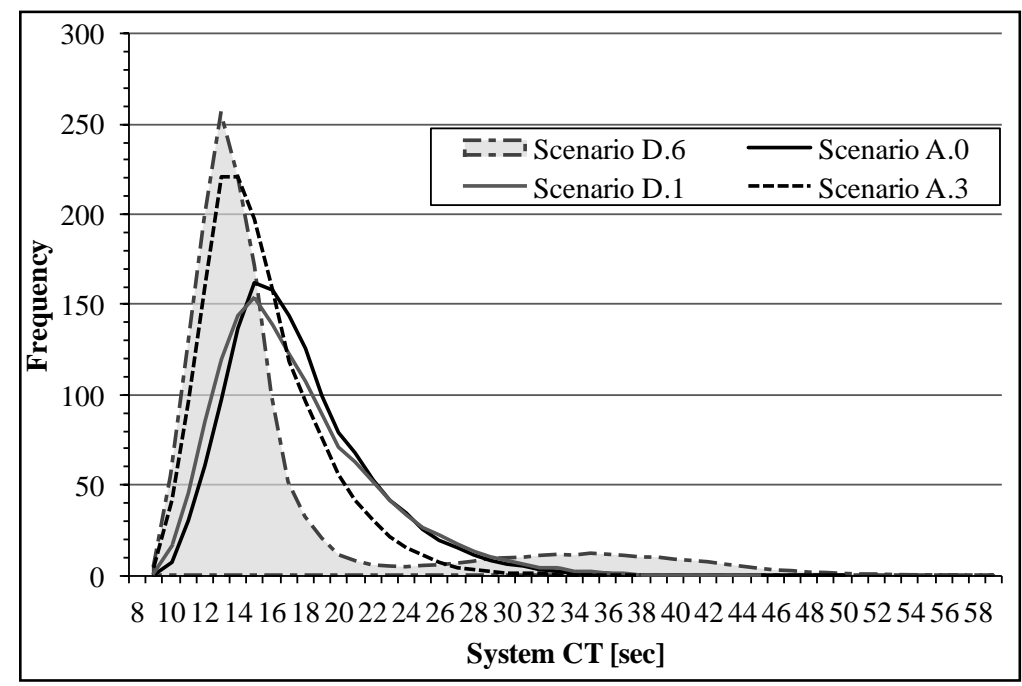

Figure 8. System output histograms for scenarios A.0, D.1, D.6 and A.3

\subsection{Scenarios E - 7 Workers, with Variable Number of Workers with Quadrant I Performances}

In Scenarios E there are 7 workers in the assembly cell and the number of workers with Quadrant I performance (worst performance - more variable and slower than the expected) is increased while the number of workers with Expected performance is reduced (Table 8).

Similarly, to what happens in scenarios D, even if there is only one worker with a worst performance than the rest, this will affect the output negatively. The number of parts produced per hour decrease: from scenario A.0 to E.1, the number of parts is reduced in $18 \mathrm{parts} / \mathrm{h}$. There is higher variability of the cycle times: when worker with Quadrant I substitutes one worker with Expected performance, the SD increases 147\% when compared to A.0 scenario.

Table 8. Scenarios E simulation outputs compared to A.0 and A.1

\begin{tabular}{lccccc}
\hline Tested Scenario & $\begin{array}{c}\text { Average } \\
\text { Output [p/h] }\end{array}$ & CT [sec] & SD [sec] & $\begin{array}{c}\text { Deviation to } \\
\text { A.0 CT }\end{array}$ & $\begin{array}{c}\text { Deviation to } \\
\text { A.0 SD }\end{array}$ \\
\hline A.0 - Expected & 199 & 18.08 & 4.19 & - & - \\
\hline E.1 - 1 Quadrant I & 181 & 19.89 & 10.37 & $10 \%$ & $147 \%$ \\
E.2 - 2 Quadrant I & 178 & 20.14 & 8.90 & $11 \%$ & $112 \%$ \\
E.3 - 3 Quadrant I & 176 & 20.36 & 7.89 & $13 \%$ & $88 \%$ \\
E.4 - 4 Quadrant I & 175 & 20.55 & 7.09 & $14 \%$ & $59 \%$ \\
E.5 - 5 Quadrant I & 173 & 20.74 & 6.44 & $15 \%$ & $34 \%$ \\
E.6 -6 Quadrant I & 172 & 20.93 & 5.78 & $16 \%$ & $23 \%$ \\
\hline A.1 -7 Quadrant I & 170 & 21.11 & 5.15 & $17 \%$ & \\
\hline
\end{tabular}


International Journal of Mathematical, Engineering and Management Sciences

Vol. 5, No. 1, 29-44, 2020

https://doi.org/10.33889/IJMEMS.2020.5.1.003

\subsection{Results Overview}

In a scenario where workers all have the same times performances, if the workers are slower than the average, then the system average cycle time will simply increase approximately with the same proportion as expected. The output variability (the system cycle time SD) is also dependent on the time performance variability of the workers, but it tends to be amplified as the workers time performance variability increases.

Another aspect to take into account is the number of workers allocated to the system. Usually in an assembly cell, the maximum number of workers should be equal to the number of workstations minus one, mainly to avoid interactions between workers. The simulation results show that as the number of workers increase $(4,7$ and 8$)$ the interactions increase, and the number of parts produced per worker decrease. In addition, if the assembly cell has fewer workers allocated, the completed parts will leave the system with a larger variability.

The results of the performed simulations studies indicate, that in the case of an assembly cell, having one or more workers with time performances better than the expected will have relatively small impact on the system average production hourly production. On the other hand, having a worker with a poorer time performance will have a higher impact (negative impact) on the system average output (Figure 9). Therefore, it can be concluded that in terms of system productivity (average $\mathrm{p} / \mathrm{h}$ ):

- It's more advantageous to have the most homogenous workers population possible in terms of time performances;

- If there's one worker which performs worse than the others, his performance will "pace" the output system performance to a slower rhythm;

- Training workers in order to improve their time performances, will increase very little the system productivity, unless all the workers are trained (and are able) to have better time performances.

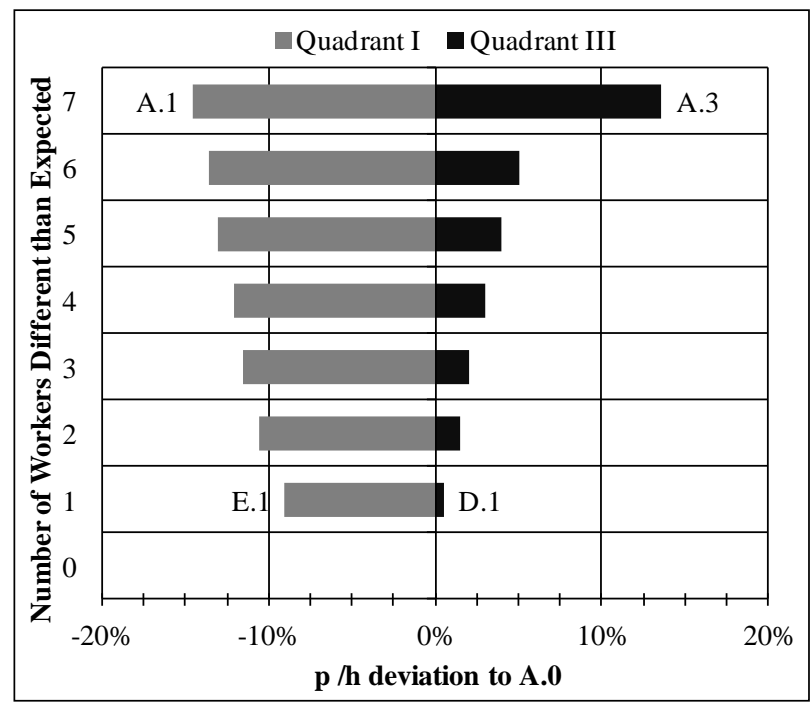

Figure 9. Impact on $\mathrm{p} / \mathrm{h}$ with number of workers different then Expected (Quadrant I and III) 
International Journal of Mathematical, Engineering and Management Sciences

Vol. 5, No. 1, 29-44, 2020

https://doi.org/10.33889/IJMEMS.2020.5.1.003

\section{Conclusions}

The several types of workers' performances used in this research were characterized in previous studies based on industrial case on high-motor content assembly tasks of an automotive industry supplier. Using simulation, these combined effects are tested in an assembly cell, in order to understand how the different performances and how combinations of different performances affect the system output. Several scenarios were tested with each type of performance, varying the number of workers assigned to the cell, and with a variable number of workers with performances different from the expected.

The results point a clear influence of the workers heterogeneity in the system output variability, being more evident when only a few low performance workers are present in a group of expected performance workers and when a large number of high-performance workers is present in a group that contains expected workers. In addition, the effect on the cycle time by adding high performance workers is fair, being higher if low performance workers are added, because the slower workers "control" the system cycle time. So, as a main conclusion, the group of workers in an assembly cell should be balanced with similar performances. If their performances are not enough to satisfy demand needs, general training to improve skills and/or tasks improvement should be the used strategy - the introduction of a few faster or fewer variable workers was proven to have little influence.

\section{Conflict of Interest}

There is no conflict of interest regarding the information provided.

\section{Acknowledgements}

This work was supported by FCT, through IDMEC, under LAETA, project UID/EMS/50022/2019.

\section{References}

Altiok, T., \& Melamed, B. (2007). Simulation Modeling and Analysis with ARENA. Elsevier Inc., California, USA. ISBN: 978-0-12-370523-5.

Bahubalendruni, M.R., Sudhakar, U., \& Lakshmi, K.V. (2019). Subassembly detection and optimal assembly sequence generation through elephant search algorithm. International Journal of Mathematical, Engineering and Management Sciences, 4(4), 998-1007.

Baines, T., Mason, S., Siebers, P.O., \& Ladbrook, J. (2004). Humans: the missing link in manufacturing simulation? Simulation Modelling Practice and Theory, 12(7-8), 515-526.

Bischak, D.P. (1996). Performance of a manufacturing module with moving workers. IIE Transactions, 28(9), 723-733.

Carnall, C.A., \& Wild, R. (1976). The location of variable work stations and the performance of production flow lines. The International Journal of Production Research, 14(6), 703-710.

Carson, J.S. (2005, December). Introduction to modeling and simulation. In Proceedings of the Winter Simulation Conference. (pp. 8). IEEE Orlando, FL, USA. 
International Journal of Mathematical, Engineering and Management Sciences

Vol. 5, No. 1, 29-44, 2020

https://doi.org/10.33889/IJMEMS.2020.5.1.003

El-Rayah, T.E. (1979). The effect of inequality of interstage buffer capacities and operation time variability on the efficiency of production line systems. International Journal of Production Research, 17(1), 7789.

Folgado, R., Henriques, E., \& Peças, P. (2013). Impact of workers with different task times on the performance of an asynchronous assembly line. In: Hinduja, S, Li, L. (eds.) Proceedings of the 37th International MATADOR 2012 Conference. Springer, London, pp. 235-238. ISBN: 9781447144793.

Folgado, R., Peças, P., \& Henriques, E. (2013). Pearformance heterogeneity within a group: an empirical study. In: Azevedo A. (eds) Advances in Sustainable and Competitive Manufacturing Systems (pp. 935946). Lecture Notes in Mechanical Engineering. Springer, Heidelberg.

Folgado, R., Pecas, P., \& Henriques, E. (2015). Mapping workers performance to analyse workers heterogeneity under different workflow policies. Journal of Manufacturing Systems, 36, $27-34$.

Hillier, F.S., \& So, K.C. (1996). On the robustness of the bowl phenomenon. European Journal of Operational Research, 89(3), 496-515.

Kala, R., \& Hitchings, G.G. (1973). The effects of performance time variance on a balanced, four-station manual assembly line. The International Journal of Production Research, 11(4), 341-353.

Kumar, R. (2019). Kaizen a tool for continuous quality improvement in indian manufacturing organization. International Journal of Mathematical, Engineering and Management Sciences, 4(2), 452-459.

Lassila A.M., Saad S.M., Perera T., Koch T., \& Chrobot J. (2005) Modelling and simulation of human centred assembly systems - a real case study. In: Camarinha-Matos L.M. (eds) Emerging Solutions for Future Manufacturing Systems. BASYS 2004. IFIP International Federation for Information Processing, 159, pp. 405-412. Springer, Boston, MA.

Maczewska, A., Polak-Sopinska, A., Wisniewski, Z., \& Krason, P. (2019, July). The concept of teaching modeling and simulation of manufacturing systems. In: Goossens R. (eds) Advances in Social and Occupational Ergonomics. AHFE 2018. Advances in Intelligent Systems and Computing, vol 792, pp. 87-96. Springer, Cham.

Maria, A. (1997, December). Introduction to modeling and simulation. In: Proceedings of the 29th Conference on Winter Simulation, Atlanta, Georgia, December 7-10, pp. 7-13.

Miltenburg, J. (2001). U-shaped production lines: a review of theory and practice. International Journal of Production Economics, 70(3), 201-214.

Peltokorpi, J., \& Niemi, E. (2018). Differences between worker pairs in manual assembly: a case study. Procedia Manufacturing, 25, 535-542.

Pike, R., \& Martinj, G.E. (1994). The bowl phenomenon in unpaced lines. The International Journal of Production Research, 32(3), 483-499.

Smith, J.S. (2003). Survey on the use of simulation for manufacturing system design and operation. Journal of Manufacturing Systems, 22(2), 157-171.

Tan, B. (1998). Agile manufacturing and management of variability. International Transactions in Operational Research, 5(5), 375-388. 